\title{
Final Report DE-FG36-01ID14008
}

Project Title:

Award Number:

Recipient:

Project Location:

Reporting Period:

Date of Report:

Written by:

Subcontractors:

Cost-Sharing Partners:

Project Contact(s):

DOE Project Team:
Multidisciplinary Graduate Curriculum in Support of the Biobased Products Industry

DE-FG36-01ID14008

Colorado School of Mines

Chemical Engineering Department

Golden, CO 80401

September 1, 2000 - September 30, 2005

September 30, 2005

John R. Dorgan

None

None

Technical: John Dorgan, 3032733539,jdorgan@mines.edu Business: Mary Mittag-Miller, 3032733405, mmittag@mines.edu

DOE-HQ contact - Amy Mannheim, 202-586-1507, amy.hanmeim@ee.doe.gov

DOE Field Project Officer - Fred Gerdeman, 303 275-4935, fred.gerdeman@go.doe.gov

DOE Contract Specialist - Margo Gorin, 303-275-4737, margo.gorin@go.doe.gov

DOE Project Monitor - Janice Ford, 303-275-4935, janice.ford@go.doe.gov 


\section{Executive Summary}

The project had a dominant education component. The project involved revising curriculum to educate traditional engineering students in the emerging field of industrial biotechnology. New classes were developed and offered. As a result, the curriculum of the Colorado School of Mines was expanded to include new content. Roughly 100 undergraduates and about 10 graduate students each year benefit from this curricular expansion. The research associated with this project consisted of developing new materials and energy sources from renewable resources. Several significant advances were made, most importantly the heat distortion temperature of polylactide (PLA) was increased through the addition of cellulosic nanowhiskers. The resulting ecobionanocomposites have superior properties which enable the use of renewable resource based plastics in a variety of new applications. Significant amounts of petroleum are thereby saved and considerable environmental benefits also result.

Effectiveness and economic feasibility of the project proved excellent. The educational activities are continuing in a sustainable fashion, now being supported by tuition revenues and the normal budgeting of the University. The PI will be teaching one of the newly developed classes will next Fall (Fall 2006), after the close of the DOE grant, and again repeatedly into the future. Now established, the curriculum in biobased products and energy will grow and evolve through regular teaching and revision. On the research side, the new plastic materials appear economically feasible and a new collaboration between the PI's group and Sealed Air, a major food-packaging manufacturer, has been established to bring the new green plastics to market.

Public benefits of the project are noteworthy in many respects. These include the development of a better educated workforce and citizenry capable of providing technological innovation as a means of growing the economy and providing jobs. In particular, the educational components addressing the production of bioethanol, biodiesel, and bioplastics provide graduates that can assist American industries in including greater renewable content in feedstocks for materials and fuels. Finally, the collaboration fostered by this grant led to the drafting of a new book entitled, Bioengineering for Sustainability: Materials and Fuels for the $21^{\text {st }}$ Century. This text will be widely available to the public interested in learning more about these important areas of technology. 


\section{Comparison of Accomplishments with Goals:}

\section{Original Project Objectives:}

1. To educate chemists, chemical engineers and materials scientists in the fields of genetic engineering, microbiology, biochemical engineering, and biobased materials by offering a selection of classes designed to broaden their traditional expertise.

2. To educate environmental scientists and microbiologists in the fields of materials science, polymeric materials, and industrial transformations by offering a selection of classes designed to broaden their traditional expertise.

3. To provide outreach services for industry that foster lifelong learning and professional development through offering short classes and web based distance learning services.

\section{Status:}

The educational development work (new classes and materials development) was completed. The Colorado School of Mines is expanded its curriculum into the realm of biological processes and products through several mechanisms, including the hiring of faculty biologists and microbiologists, the establishment of centers for biomechanical and biomaterials engineering, and the promotion of an undergraduate minor in the Life Sciences. The goal of this project is to use these and other available avenues to prepare graduate students in Chemical Engineering, Materials Science, and Environmental Science and Engineering for careers in the Biobased Products Industry.

At the Colorado School of Mines, each Ph.D. student is required to complete a 12-credit minor in an outside discipline. A primary goal of the present project was to structure a Biobased Products graduate minor by developing new biomaterials and biotechnology classes to complement existing courses in engineering, materials science, biochemistry, and microbiology. A second primary goal of the project is to incorporate training in biotechnology into the Environmental Science and Engineering graduate curriculum through development of new courses, and a third primary goal is to complement these curriculum development efforts with the establishment and expansion of graduate research projects in the Biobased Products field.

The courses necessary for the Biobased Products Minor were developed and introduced as an official Graduate Minor occurred in 2002-2003. The minor requires 18 credits and 9 new credit hours have been developed under the grant including:

- ESGN 586: Microbiology of Engineered Environmental Systems

- ESGN 596: Molecular Environmental Biotechnology

- CHEN 426 Biochemical Engineering

A recent development under the auspices of the grant is that the two Pis have co-developed a draft of a textbook entitled, Bioengineering for Sustainability: Materials and Fuels for the $21^{\text {st }}$ Century. The support provided under this grant is directly responsible for the ability of the researchers to collaborate and produce this document. A draft version of some chapters is appended to this final report. 
New class web pages have been developed for the above mentioned classes. These web pages and the accompanying electronic media are now available.

In summary, the objectives for the project were met or exceeded. New educational infrastructure was created and is now supported in a sustainable manner. In addition, innovative and important research objectives were met that are allowing the displacement of petroleum-based plastics with renewable resource based ones. 


\section{Project Activities:}

During the 2001-2002 academic year, the following classes were developed and delivered, with the exception of CHEN 426 which was delivered during the Spring of 2003 semester. The delivered courses were met with great student enthusiasm, obtained high enrollments $(\sim 10$ per course) for this small university, and have become permanent parts of the CSM curriculum:

- ESGN 586: Microbiology of Engineered Environmental Systems. Graduate-level course covering the microbiology of bioremediation, biodegradation, biotransformations, and biological waste treatment, with the theme that microbial processes are becoming increasingly valuable and commercially viable biological products.

- ESGN 596: Molecular Environmental Biotechnology. Graduate-level course covering the mechanisms and applications of genetic engineering, including case studies of production of bio-based products and processes such as biodegradable polymer production, biopesticide synthesis, biofuel generation, and biosyntheses of enzymatic detergents, surfactants, biological dyes, and vitamins.

- CHEN 498: Introduction to Biochemical Engineering Senior level or first year graduate student class covering the basics of industrial biotechnology from a chemical engineering perspective. Basics of biochemistry and molecular biology, bioreactor design and operation, bioseparations.

Track Development. During the 2001-2002 academic year, the Environmental Science and Engineering Division established a graduate coursework track in Environmental Biotechnology that directly prepares M.S. students for careers in the engineering of biological processes for both process and product-based applications. Track requirements include:

- CHGN 428: Introductory Biochemistry

- ESGN 541: Biochemical Treatment Processes

- ESGN 586: Microbiology of Engineered Environmental Systems

- ESGN 596: Molecular Environmental Biotechnology

Biobased Minor Development. The courses necessary for the Biobased Products Minor are now developed, and introduction of the program as an official Graduate Minor is planned for 20022003. The minor requires 12 units from the following courses:

- ESGN 586: Microbiology of Engineered Environmental Systems

- ESGN 596: Molecular Environmental Biotechnology

- CHEN 426 Biochemical Engineering

Research Development. Several graduate students were partially supported during 2001 and 2002 by funds from the grant, as listed below:

- Scott Plummer (advisor: Ahmann) - Improvement of the iron hydrogenase enzyme in the green alga Chlamydomonas reinhardtii for oxygen-tolerant production of $\mathrm{H}_{2}$.

- Peggy Churchill (advisor: Ahmann) - Isolation and characterization of algal mutants for improved $\mathrm{H}_{2}$ production. 
During the 2002-2003 academic year, the following classes were delivered. The delivered courses were met with great student enthusiasm, obtained high enrollments for a small university ( $\sim 10$ per course in graduate level and $\sim 20+$ at the undergraduate level), and have become permanent parts of the CSM graduate curriculum:

- CHEN 498: Introduction to Biochemical Engineering Undergraduate-level course covering basics of biochemistry, enzymology, and fermentations. Study of bioreactor configuration and optimization and case studies of important biochemical industrial processes (lactic acid, ethanol, etc.).

- ESGN 586: Microbiology of Engineered Environmental Systems. Graduate-level course covering the microbiology of bioremediation, biodegradation, biotransformations, and biological waste treatment, with the theme that microbial processes are becoming increasingly valuable and commercially viable biological products.

- ESGN 596: Molecular Environmental Biotechnology. Graduate-level course covering the mechanisms and applications of genetic engineering, including case studies of production of bio-based products and processes such as biodegradable polymer production, biopesticide synthesis, biofuel generation, and biosyntheses of enzymatic detergents, surfactants, biological dyes, and vitamins.

Biobased Minor Development. During the 2002-2003 academic year, the CSM campus developed and approved the BELS track for undergraduate students to pursue a biological sciences minor The courses necessary for the Biobased Products Minor are now being offered. The minor requires 12 units from the following courses:

- ESGN 586: Microbiology of Engineered Environmental Systems

- ESGN 596: Molecular Environmental Biotechnology

- CHEN 426 Biochemical Engineering

Research Development. Graduate students and postdocs have been partially supported by funds from the grant, as listed below:

- Scott Plummer (advisor: Ahmann) - Improvement of the iron hydrogenase enzyme in the green alga Chlamydomonas reinhardtii for oxygen-tolerant production of $\mathrm{H}_{2}$.

- Peggy Churchill (advisor: Ahmann) - Isolation and characterization of algal mutants for improved $\mathrm{H}_{2}$ production.

- Lihong Bao (advisor Dorgan) - Permeation properties of BioPlastics and blends thereof 
During the 2003-2004 academic year the focus turned to graduate student training and research activities due to the fact that the course development educational objectives had been met and the budget from DOE had been cut (year three funding was reduced from roughly $\$ 130,000$ to $\$ 25,000)$. A new Ph.D. student, Ms. Birgit Braun, was partially supported under the program. She focused on the synthesis of novel supramolecular nanocomposites containing PLA (polylactide, a corn based plastic). The other constituents of the novel plastics are also derived directly from plants. In particular, we used cellulosics from woody plants and starches from agricultural crops. The creation of PLA-graft-cellulose supramolecular structures holds the promise of addressing one of the key obstacles of greater utilization of plant based materials. Namely, PLA suffers from a low heat distortion temperature as a result of the fact that its glass transition temperature is about $58 \mathrm{C}$. The supramolecular nanostructures developed using partial support from this project have higher heat distortion temperatures.

Professor Dorgan also organized the annual meeting of the Bioenvironmental Polymer Society (BEPS) which was held on August 10th-13th in Denver. Professor Dorgan served as the Vice President 2004 and as President of BEPS in 2005. This is considered an educational outreach activity under the grant.

During the 2004-2005 academic year our research continued and publications resulted. In addition, work was completed on the text, Bioengineering for Sustainability: Materials and Fuels for the $21^{\text {st }}$ Century. Our research work under the grant was featured in Chemical and Engineering News, the biweekly publication of the American Chemical Society. In an article entitled, Green Polymers field is Blossoming (Michael Freemantle in Chemical and Engineering News (October $2^{\text {nd }}, 2005$ issue) or research advances in making improved forms of biobased plastics were cited as significant developments. This is primarily die to the fact that we are exploiting nanotechnology to improve the thermophysical properties of biobased plastics.

Our work has proven that reactively prepared nanocomposites of PLA with microcrystalline cellulose do in fact show enhanced heat distortion temperatures. Present formulations have HDTs in excess of $100 \mathrm{C}$ thereby allowing the use of biobased PLA in a variety of hot food and hot drink applications.

\section{Products Developed:}

\section{A. Publications}

1. Gas Solubility of Carbon Dioxide in Poly(lactic acid) at High Pressures, N. S. Oliveira, J. Dorgan, J. A. P. Coutinho, A. Ferreira, J. L. Daridon, I. M. Marrucho, Journal of Polymer Science: Part B: Polymer Physics, Vol. 44, 10101-1019 (2006)

2. Novel Reactively Compatibilized Microcomposites, John R. Dorgan and Birgit Braun

3. Polymer Preprints 46(1), 287, (2005)

4. Ecobionanocomposites: A New Class of Green Materials, John R. Dorgan and Birgit Braun

5. Polymeric Materials: Science and Engineering Preprints 93, 954, (2005)

6. Poly(lactic acid) - A Brief Overview, J. R. Dorgan, B. Braun, J. R. Wegner, D. M. Knauss, in Degradable Polymers and Materials, Carmen Scholtz and Kishan Khemani, Eds., ACS Symposium Series Books, ACS Books, Washington DC, In Press 2006. 
7. Fundamental Solution and Single Chain Properties of Polylactides, J. Janzen, J.R. Dorgan, D.K. Knauss, et. al., Journal of Polymer Science: Part B: Polymer Physics, Vol. 43, 3100-3111 (2005)

8. Optical Properties of Polylactides, Matthew H. Hutchinson, John R. Dorgan, Daniel M. Knauss, Sukhendu B. Hait, Journal of Polymers and the Environment, 14(2), 1-6 (2006).

9. Reactively Compatibilized Cellulosic Polylactide Microcomposites, Birgit Braun, John R. Dorgan, Daniel M. Knauss, Journal of Polymers and the Environment 14(1), 49-58, (2006).

10. Melt Rheology of Variable L-content Poly(lactic acid), J.R. Dorgan, J. Janzen, D.K. Knauss, et. al., Journal of Rheology, 49(3), 607-619 (2005).

11. Gas sorption in poly(lactic acid) and packaging materials. N. Oliveira, J. Oliveira, T. Gomes, A. Ferreira, J. Dorgan, I.M. Marrucho, Fluid Phase Equilibria, 317-324 (2004)

12. Local and global dynamics of polylactides. Mierzwa, M.; Floudas, G.; Dorgan, J.; Knauss, D.; Wegner, J. Journal of Noncrystalline Solids, 2002, vol. 307-310, pp. 296-303

13. Effects of Molecular Architecture on Two-Step Melt-Spun Poly(lactic acid) Fibers, J.A. Cicero, J.R. Dorgan, J. Garrett, J. Runt, J.S. Lin, J. Appld. Polym Sci., v.86, pp.28392846 (2002).

14. Supramolecular Morphology of Two-Step Melt-Spun Poly(lactic acid) Fibers, J.A. Cicero, J.R. Dorgan, J. Janzen, J. Garrett, J. Runt, J.S. Lin, J. Appld. Polym Sci., v.86, pp.2828-2838 (2002).

15. Phosphite stabilization effects on two-step melt-spun fibers of polylactide, Cicero, J. A.; Dorgan, J. R.; Dec, S. F.; Knauss, D. M. Polymer Degradation and Stability, 2002, vol. 78, no. 1, pp. 95-105

16. Physical Properties and Fiber Morphology of Poly(lactic acid) obtained from Continuous Two-Step Melt Spinning. J. Cicero, J.R. Dorgan, J. Polymers and Environ., pp.1-15, January (2001)

17. Gas Permeation Properties of Poly(lactic acid), H.J. Lehermeier, J.R. Dorgan, and J.D. Way, Journal of Membrane Science 190, pp. 243-251 (2001).

18. Melt Rheology of Poly(lactic acid) : Consequences of Blending Chain Architectures, H.J. Lehermeier, and J.R. Dorgan, Polymer and Engineering Science 41(12), pp.2172-2184 (2001).

\section{B. Web sites}

http://www.mines.edu/Academic/chemeng/faculty/jdorgan/

http://blackboard.mines.edu/webapps/portal/frameset.jsp?tab=courses\&url=/bin/common/course. pl? course_id=_2647_1

http://blackboard.mines.edu/webapps/portal/frameset.jsp?tab=courses\&url=/bin/common/course. pl? course_id=_2274_1

\section{Collaborations Fostered}

A wide variety of collaborations were fostered, at least in part, due to the present grant. These include the direrct collaboration between the PI and co-PI that led to the draft manuscript of the book, Bioengineering for Sustainability: Materials and Fuels for the $21^{\text {st }}$ Century. In addition, ties between CSM and NREL were enhanced; presently there is a Memorandum of 
Understanding (MOU) in place to facilitate research between the CSM group and NREL by allowing shared use of laboratory facilities. CSM graduate students can be badged for security clearance and facile access to NREL laboratories and facilities. Finally, having publishable research results in the PLA plastics area has led to additional interactions with USDA researchers (largely through the BEPS meetings) and with several industrial research groups including Ford Motors, Kodak, and Sealed Air. Additionally, collaboration with other academic groups, notably at Clemson University, have also been enhanced.

\section{Technologies}

The development of PLA bioplastics with enhanced properties represents a significant advance in the state-of-the-art for biobased materials. This has led to additional funding and the collaboration with Sealed-Air is working towards commercialization of these new materials for use in food packaging applications

\section{E. Patents: A patent entitled, HIGH MODULUS POLYMER COMPOSITES AND METHODS OF MAKING THE SAME was filed with the USPTO.}

\section{Conclusions:}

Despite the reductions in funding mandated by the DOE, the project met the basic goals and objectives. The project involved revising curriculum to educate traditional engineering students in the emerging field of industrial biotechnology. The curriculum of the Colorado School of Mines was expanded to include new content. Roughly 100 undergraduates and about 10 graduate students each year benefit from this curricular expansion. The research associated with this project consisted of developing new materials and energy sources from renewable resources. Several significant research advances were made. Most importantly the heat distortion temperature of polylactide (PLA) was increased through the addition of cellulosic nanowhiskers. The resulting ecobionanocomposites have superior properties which enable the use of renewable resource based plastics in a variety of new applications. Significant amounts of petroleum are thereby saved and considerable environmental benefits also result.

Effectiveness and economic feasibility of the project proved excellent. The educational activities are continuing in a sustainable fashion, now being supported by tuition revenues and the normal budgeting of the University.

Public benefits of the project are noteworthy in many respects. These include a better educated workforce capable of providing technological innovation as a means of growing the economy and providing jobs. Educational components can assist American industries in including greater renewable content in feedstocks for materials and fuels. Finally, the collaboration fostered by this grant led to the drafting of a new book entitled, Bioengineering for Sustainability: Materials and Fuels for the $21^{\text {st }}$ Century. This text will be widely available to the public interested in learning more about these important areas of technology. 
Appendix A: Chapter 1 of Bioengineering for Sustainability: Materials and Fuels for the $21^{\text {st }}$ Century.
A.
Current Status of Energy and Materials Feedstocks
B. Biotechnology for Petroleum Replacement
C. Statement of Purpose
D. Terms and Definitions
E. References

\section{A. Current Status of Energy and Materials Feedstocks}

The petroleum resource. Resource shortages are a natural consequence of the utility of the resource combined with human ingenuity. As a new resource is discovered, people invent uses for it in proportion to its adaptibility; increased uses typically increase the demand for it, which often results in increased production, which increases the opportunity for new uses to be discovered, and so on. In the case of petroleum, this cycle has progressed to such an extent that developed world economies are utterly dependent on it for heat, food (through agriculture), shelter (through synthesis of construction materials), and transportation.

In the United States, for example, petroleum use has increased steadily from approximately 9.8 million barrels per day in 1960 to 21 million barrels per day in 2005 (1). The present rate of demand increase is $\sim 1.5 \%$ per year, with the result that U.S. demand is expected to increase $37 \%$ over 2004 levels by 2025 (2). Within this demand, transportation and industry, including plastics and materials production, consume the greatest shares at $\sim 66 \%$ and $\sim 25 \%$ respectively. Comparable increases have been observed in other developed countries as well $(3,4)$. If petroleum were plentiful, widely distributed, and environmentally benign, this situation would be no cause for concern. Unfortunately, though, this is not the case.

First, the demand of the developed economies for petroleum is now comparable to known reserve limits. For comparison, an estimated 875 billion barrels of oil have been consumed since the dawn of the oil age (5), while 1.7 trillion barrels remain in proven reserves (within oil fields discovered but not yet pumped out), and another estimated 900 billion remain to be discovered (6). Of the 875 billion consumed, however, greater than $60 \%$ (550 billion) have been consumed since 1975; with world demand continuing to rise at $\sim 2 \%$ per year, the world production peak is estimated to occur between 2026 and 2047 (5). Within the U.S., crude oil production is expected to peak in 2010 (2), and the remainder of the petroleum that is easily accessible given both 
geological and political constraints is expected to peak in that approximate time frame as well (6).

This raises the second issue, that of petroleum accessibility, given both geological and political constraints. Geological factors dictate that not all petroleum is equally accessible: while fields may lie in temperate zones within several hundred feet of the surface, those have understandably been the first to be exploited, leaving oil beneath oceans, in remote Arctic regions, tightly associated with sands, and/or laden with impurities as an increasing component of that that remains to be exploited. Technological advances have greatly increased the proportion of petroleum that can be extracted from the earth, once discovered, but often at high operational and environmental cost.

Political factors also contribute to petroleum accessibility. While the U.S. was once the world's greatest petroleum producer, it and many other developed countries are now net importers: the U.S. now imports approx. $56 \%$ of its demand, or $\sim 11.2$ million barrels per day $(7,8)$. Notably for U.S. interests, it is not only the greatest consumer of world petroleum resources, demanding $\sim 25 \%$ of the global total production (4), but also the greatest importer, with nearly double the net imports of second-ranked Japan (9). Of the 1.7 trillion barrels of oil in the world's proven reserves, over half of those are located in the Middle East. Petroleum resources are therefore becoming increasingly concentrated in regions of the world, particularly the Middle East, that have historically been politically unstable and/or unfriendly to Western interests (6). Finally, petroleum is far from environmentally benign. Petroleum combustion releases carbonaceous gases, principally $\mathrm{CO}_{2}, \mathrm{CO}$, and $\mathrm{CH}_{4}$, as well as sulfurous gases such as $\mathrm{SO}_{2}$. Decades of climate and atmospheric composition data are now confirming the link between increasing concentrations of greenhouse gases such as those emitted by combustion of fossil fuels and increasing global temperatures (10). In addition, concerns are growing about the volume of discarded wastes that the U.S. and other countries produce. Global consumption of petroleum-based thermoplastics, the greatest component, now exceeds 100 million tons per year, of which approximately half is discarded within two years of production. Much of the other half, used to generate products with longer lifetimes, is just beginning to enter the waste stream, with the result that plastic waste generation is expected soon to exceed the growth in consumption (11). This, in turn, is expected to create a considerable demand on landfill space (12). An accompanying problem is that wealthy countries can export such wastes to poorer countries. 
Although these practices have been addressed through measures such as the Basel Ban, diminishing waste volumes is the most straightforward solution to exploitation of vulnerable peoples and natural areas (13). As a result, the impetus for transition from fossil fuels to renewable energy sources and materials feedstocks is resulting as much from environmental considerations as it is from concerns about future conflict over petroleum resources.

Benefits of petroleum replacement. Numerous technologies are under development for the replacement of petroleum as the primary energy source and materials feedstock in developed countries. Wind, solar, hydroelectric, geothermal, and biomass-derived power will each be called upon to contribute to the post-petroleum economy, and conservation measures are also expected to receive greatly increased attention. Materials derived from biological molecules are also gaining diversity and availability.

To what extent can petroleum be replaced, and by what alternatives, within the next decades? While this potential is debatable, a realistic best-case scenario can be presented given recent projections. In April, 2005, a report by the U.S. Department of Energy and U.S. Department of Agriculture estimated that the U.S. could quite feasibly produce 1 billion dry tons of biomass feedstock (over half of which is waste) per year, enough to displace $30 \%$ or more of the U.S. present petroleum consumption for fuels and materials, by 2030 (14). When this estimate is combined with projections of solar and wind energy together providing $20 \%$ of the power demand in the industrialized world by that time, it appears that biological resources could become important contributors to the evolution of a post-petroleum world. Under these projections, $\mathrm{CO}_{2}$ emissions could peak before 2050 and conventional fossil fuel use could be virtually eliminated by 2100 (6).

Unique contributions from biotechnology. The application of biotechnology to the production of commodities, notably fuels, chemicals, and structural materials, increases the array of options available to supply sustainable resources and preserve environmental quality. In particular, through the use of biological feedstocks, biotechnology has the potential to minimize greatly the overwhelming dependence of developed countries, particularly the U.S., on petroleum and other non-renewable fossil fuels for production of fuels and plastics.

Numerous mechanical, geothermal, and electrical technologies offer valuable contributions to issues of energy independence and pollution prevention (15). At the same time, several unique advantages are brought by bioengineering and bioproducts that will be highlighted in this text. 
First, many biotechnologies use the abundant, renewable, and potentially sustainably-produced resource of plant biomass as the primary feedstock for liquid biofuels, biochemicals, and biomaterials. Cellulosic and other biomass is currently available at the commodity scale and is increasingly cost-competitive with petroleum, especially when environmental costs are included, on both energy and mass bases (16). Indeed, the land resources of the United States are capable of producing a sustainable supply of biomass sufficient to displace $30 \%$ or more of the country's present petroleum consumption, amounting to approximately 1 billion dry tons of biomass feedstock per year (14).

Second, microbiotechnologies have the potential to use simple organic and inorganic feedstocks in microbe-based bioreactors that generate desired products directly, without plant biomass intermediates. For example, photosynthetic microbial biohydrogen production requires only sunlight, $\mathrm{CO}_{2}$, salts, and water (17), and bioplastic precursors such as polylactic acid and polyhydroxybutyrate can be made directly by microbes as well $(18,19)$.

Third, biotechnologies make use of enzymes, proteinaceous catalysts that are often exquisitely selective and provide high rates of product generation. Unlike other catalysts, enzymes can be manipulated genetically to improve parameters such as substrate affinity, specificity, and catalytic rate, as well as tolerance to process conditions, longevity, and even production rate of the enzyme itself by the host cell.

Finally, as a result of the above, many biotechnologies are able to avoid use of toxic feedstocks and processing reagents that are necessitated by conventional methods and thereby minimize toxic wastes. For example, biosynthesis of the denim dye, indigo, requires only glucose as substrate, in contrast to the conventional synthesis that requires benzene or other aromatic solvents (20).

Bioengineering for sustainability is an emerging area of both intellectual endeavor and industrial practice. The economic driving forces, the importance of feedstock, and the scale of production all distinguish this arena of biotechnology from the pharmaceutical and nutritional sectors. While fossil fuel-based economies typically evolve from a relatively low-value commodity (e.g. kerosene for lighting) to intermediate-value materials (gasoline, plastics) and ultimately to valuable specialty chemicals (cosmetics, pharmaceuticals), it appears that the biobased economy is progressing from high-value products (pharmaceuticals) to those of intermediate value (industrial catalysts, plastics). As biotechnology evolves and matures, the production of large- 
scale, relatively low-value products such as fuels is becoming increasingly attractive and economically feasible.

\section{B. Current Challenges}

Cellulose stability. The greatest impediment to widespread application of bioengineering for production of commodities is currently the general absence of low-cost processing technologies for biomass. Challenges associated with the conversion of plant biomass into useful products are dominated by the chemical stability of cellulose within biomass (Fig. 1), causing it to resist modification and therefore require valuable enzymes or other catalysts, as well as special processing conditions (21). Advances are therefore greatly needed in both enzymatic and nonenzymatic biomass pretreatment technologies, as well as in the development of efficient productproducing microbes and fermentation bioreactor technologies, the latter of which would directly benefit non-biomass-consuming processes as well. The generation of high-value co-products has the potential greatly to offset expenses of processing any feedstock, showing that exploration of the diversity of products that a process or feedstock can yield is also of central importance to realization of true, profitable, economically resilient biorefineries.

Engineering optimal organisms. Genetic and metabolic engineering techniques are now being used to address the microbial and enzymatic problems of biocommodity production from hundreds of different angles. The central goal, in virtually all cases, is the development of organisms that can use low-cost substrates, give high product yields, and/or exhibit robustness in temperature and $\mathrm{pH}$ extremes characteristic of many industrial environments. The rapidity of development of techniques for manipulation and/or analysis of gene sequences and expression patterns, as well as the exponential rate of accumulation of genetic information about numerous industrial microorganisms, are enormous forces propelling the field of bioengineering forward. Problems that were previously thought unassailable are now dispatched routinely, and resources have never been more abundant for the pursuit of new ideas (22).

Bioreactors and Bioseparations. Similarly, reactor and separations technologies must play important roles in the development of economically feasible biorefineries, as these processing steps often contribute the greatest expense to the final products. At early stages of development, new bioengineering processes often benefit greatly from combination of separate components. For example, integrating unit operations, as into reactor-separators and other novel processes, often provides immediate improvements in efficiency. Similarly, integrating individual 
production steps into a multi-product biorefinery, and integrating biorefineries into the broader economic and environmental systems in which they function, are important avenues to economic feasibility. To evaluate energy, material, and cost efficiencies of such systems, Life Cycle Analysis (LCA) tools are invaluable and are themselves undergoing rapid development (23). An enormous barrier exists in the funding and deployment of any pioneer manufacturing plant, and federal programs may be necessary to provide loan guarantees and other incentives to encourage enterprise in this direction (24).

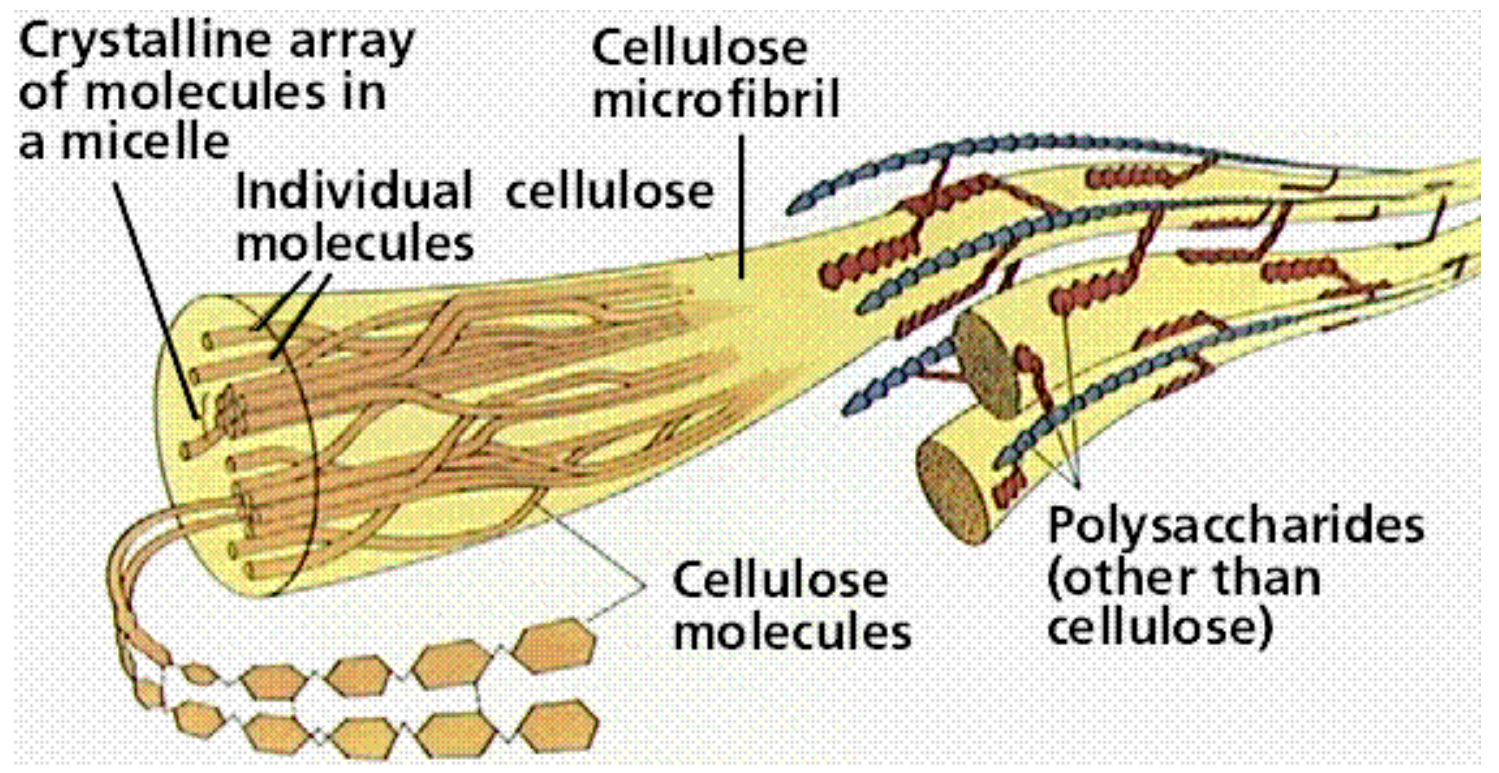

Figure 1. Structure of cellulose as it occurs in a plant cell wall. Reprinted from Purves et al., Life: The Science of Biology, 4th Edition, by Sinauer Associates (www.sinauer.com) and WH Freeman (www.whfreeman.com), with permission.

\section{Statement of Purpose}

This text hopes to serve several purposes. The first objective is to explore the realm of current and developing bioengineering technologies within the sub-fields of sustainable biomaterials and biofuels. These renewable resource based technologies benefit environmental integrity. Second, the text seeks to identify the most promising and most essential areas of endeavor within each field, thus highlighting top priorities for further research and development. As a third objective, the book examines the technological challenges and/or barriers to the progress of the given technologies. Fourth and finally, the text attempt to persuade readers both of the urgency with which advancement of bioengineering and other sustainable technologies for 
petroleum independence and pollution prevention must be pursued and of the great wealth of resources already available with which to pursue them.

\section{Terms and Definitions}

The field of Bioengineering for Sustainability as outlined is immense. A tremendous number of talented and energetic people are working to bring the elements outlined in the preceding paragraphs into reality. To create a coherent, focused, and thorough document, the authors have limited the discussion to the areas of energy and materials, and provide here a set of terms that further define, limit, and clarify the topics involved.

Bioengineering. In its broadest sense, this term is applied to the manipulation, influence, or purposeful design of any entity, material, or process involving biological components. For the purpose of this document, however, a more restricted definition is adopted, in which the engineering itself must involve the manipulation and/or exploitation of biological components themselves to accomplish the desired task.

Pollution prevention. In the context of this document, "pollution prevention" is restricted to the description of processes that deliberately avoid the generation of environmentally deleterious substances. Processes that reclaim, recycle, or degrade such substances, once generated, are excluded.

Materials. This term is broadly used to represent any form of matter.

Biopolymers, bioplastics. These terms are used specifically to represent high-molecular-weight structural materials that can be shaped or otherwise manufactured into useful articles for human use.

Energy and fuels. "Energy" in this document emphasizes biological, biologically-produced, or biologically-modified materials or processes capable of generating heat or power. Thus, all significant biofuels (bioalcohols, biodiesel, biohydrogen) are included, in addition to conventional fuels that have been enzymatically treated to reduce generation of pollutants.

Economics and commercialization. In a market economy, the financial aspects of a new technology inevitably have a major impact on its adoption. Indeed, the majority of technological limitations and research needs described below derive their importance from the need to make pollution prevention technologies competitive with their conventional counterparts. Nevertheless, as a review of the state of the science, thorough analyses of the process economics 
of each technology are beyond the scope of this work. Many excellent reviews of this aspect exist, however, and are cited in the text.

\section{E. References}

(1) Energy Information Administration (2005) Annual Energy Outlook 2005, http://www.eia.doe.gov/oiaf/aeo/.

(2) Reuters (2004) Petroleum demand to grow 37\% by 2025 -- EIA, MSNBC, Washington, D. C.

(3) U.S. Department of Energy, Energy Information Administration (2003) Annual Energy Review 2002, Washington, D.C., http://www.bts.gov/publications/pocket guide to transportation/2004/html/figure 06 table.html (4) Bureau of Transportation Statistics (2004) Overview of U.S. Petroleum Production, Imports, Exports, and Consumption, Washington, D.C., http://www.bts.gov/publications/national transportation statistics $/ 2004 / \mathrm{html} / \mathrm{table} 0401 . \mathrm{html}$ (5) Wood, J. H., G. R. Long, and D. F. Morehouse (2004) Long-Term World Oil Supply Scenarios, Energy Information Agency, http://www.eia.doe.gov/pub/oil gas/petroleum/feature articles/2004/worldoilsupply/oilsupply04. html.

(6) Roberts, P. (2004) The End of Oil. Houghton Mifflin, Boston.

(7) U.S. Department of Energy, Energy Information Administration (2003) Net Imports of Crude Oil and Petroleum Products into the United States by Country, 2003, Washington, D.C., Table 29 Petroleum Supply Annual 2003, Volume 1, page 68.

(8) U.S. Department of Energy, Energy Information Administration (2004) U.S. Petroleum Imports and Exports, Washington, D.C., http://www.eia.doe.gov/oil_gas/petroleum/info glance/importexport.html

(9) U.S. Department of Energy, Energy Information Administration (2001) Top Petroleum Net Importers, Washington, D.C., http://www.eia.doe.gov/emeu/security/topimp.html (10) U.S. Environmental Protection Agency (2000) Global Warming -- Climate, http://yosemite.epa.gov/oar/globalwarming.nsf/content/Climate.html. (11) Greenpeace (1998) The Plastics Boom and the Looming PVC Waste Crisis, Amsterdam, The Netherlands, http://archive.greenpeace.org/comms/pvctoys/reports/loomingcontents.html (12) Manchester Metropolitan University (2004) Atmosphere, Climate, \& Environment Information Programme: Waste Fact Sheet Series, Manchester, UK, http://www.ace.mmu.ac.uk/Resources/Fact_Sheets/Key_Stage_4/Waste/05.php (13) Basel Action Network (1997) The Basel Ban: A Triumph Over Business-As-Usual, Basel, Switzerland, http://www.ban.org/about_basel_ban/jims_article.html

(14) U.S. Department of Energy and U.S. Department of Agriculture (2005) Biomass as Feedstock for a Bioenergy and Bioproducts Industry: The Technical Feasibility of a Billion-Ton Annual Supply, Oak Ridge, TN, DOE/GO-102995-2135.

(15) Hester, R. E., and R. M. Harrison, Eds. (2003) Sustainability and Environmental Impact of Renewable Energy Sources. Springer-Verlag Telos, New York, NY. (16) Lynd, L. R., and C. E. Wyman (1999) Testimony before the Senate Committee on Agriculture, Nutrition, and Forestry on Senate Bill S935: Sustainable Fuels and Chemicals Act of 1999. Thayer School of Engineering, Dartmouth College, Dartmouth, NH. 
(17) Levin, D. B., L. Pitt, and M. Love (2004) Biohydrogen production: prospects and limitations to practical application, Intl J Hydrogen Energy 29:173-185.

(18) Salehizadeh, H., and M. C. van Loosdrecht (2004) Production of polyhydroxyalkanoates by mixed culture: recent trends and biotechnological importance, Biotechnol Adv 22:261-279.

(19) van Maris, A. J. A., W. N. Konings, J. P. van Dijken, and J. T. Pronk (2004) Microbial export of lactic and 3-hydroxypropanoic acid: Implications for industrial fermentation processes, Metabo Eng 6:245-255.

(20) Berry, A., T. C. Dodge, M. Pepsin, and W. Weyler (2002) Application of metabolic engineering to improve both the production and use of biotech indigo, J Ind Microbiol Biotechnol 28:127-133.

(21) Klemm, D., B. Philipp, T. Heinze, U. Heinze, and W. Wagenknecht (1998) Comprehensive Cellulose Chemistry, Volume 2: Functionalization of Cellulose. Wiley-VCH.

(22) Ausubel, F. M., R. Brent, R. E. Kingston, D. D. Moore, J. G. Seidman, J. A. Smith, and K. Struhl, Eds. (1988 (updated quarterly)) Current Protocols in Molecular Biology, Ringbound Edition. Greene Publishing Associates.

(23) Hauschild, M. Z. (2005) Assessing Environmental Impacts in a Life-Cycle Perspective, Environ Sci Technol 39:81A-88A.

(24) Ingram, L. (2005) Personal communication. 